\title{
Apoptosis inducers in chronic lymphocytic leukemia
}

\author{
Christian Billard ${ }^{1,2}$ \\ ${ }^{1}$ INSERM U 872, Centre de Recherche des Cordeliers, Equipe 18, Paris, France \\ 2 Université Pierre et Marie Curie (UMRS 872), Paris, France. \\ Correspondence to: Christian Billard, email: christian.billard@crc.jussieu.fr \\ Keywords: CLL; impaired cell death program; apoptosis-targeted therapies; apoptosis inducers; BCl-2 family proteins. \\ Received: October 8, 2013 \\ Accepted: November 18, 2013 \\ Published: November 19, 2013 \\ This is an open-access article distributed under the terms of the Creative Commons Attribution License, which permits unrestricted use, \\ distribution, and reproduction in any medium, provided the original author and source are credited.
}

\section{ABSTRACT:}

Chronic lymphocytic leukemia (CLL) is characterized by a typical defect in apoptosis and is still an incurable disease. Numerous apoptosis inducers have been described. These synthetic compounds and natural products (mainly derived from plants) display antileukemic properties in vitro and in vivo and some have even been tested in the clinic in CLL. They act through several different mechanisms. Most of them involve proteins of the $\mathrm{Bcl}-2$ family, which are the key regulators in triggering the mitochondrial pathway of caspase-dependent apoptosis. Thus, the Mcl-1/Noxa axis appeared as a target. Here $I$ overview natural and synthetic apoptosis inducers and their mechanisms of action in CLL cells. Opportunities for developing novel, apoptosis-based therapeutics are presented.

\section{INTRODUCTION}

Apoptosis is a physiological cell suicide program that is essential for the regulation of development, the maintenance of homeostasis and the prevention of tumorigenesis. Evading the apoptotic program is one of the hallmarks of cancer and represents an important mechanism in clinical resistance to therapies $[1,2]$. This is particularly true for chronic lymphocytic leukemia (CLL), a currently incurable condition that is clearly characterized by impaired apoptosis. The development of therapeutic strategies that target apoptosis in CLL is therefore a very important issue.

\subsection{Pathways in caspase-dependent apoptosis}

The apoptotic machinery comprises two main activation pathways (the extrinsic and the intrinsic pathways) and an execution phase mediated by proteases of the caspase family [3]. The extrinsic pathway (also known as the death receptor pathway) is triggered by ligation of death receptors (TNF-R, Fas, DR4) by their respective ligands (TNF, Fas L, TRAIL) and recruitment of adapter molecules, which activates the initiator caspase-8. The intrinsic pathway (also known as the mitochondrial pathway) integrates various intracellular signals at the mitochondrial membrane and is regulated by Bcl-2 family proteins (that share at least one of the four Bcl-2 homology domains, $\mathrm{BH} 1$ to 4). The prosurvival members of the family (Bcl-2, Bcl-xL, Bcl-w, Mcl-1 and A1) sequester the proapoptotic members Bax and Bak. Upon stimulation, the family's BH3-only members (socalled because they only have the BH3 domain) Bim, Puma, Bid, Bad, Noxa, etc., bind to and antagonize the prosurvival proteins. The sequestered Bax and Bak are thus released from their prosurvival ligands and then activated. There is another activation pathway in which Bax and Bak are directly activated by certain BH3-only proteins [3]. In any event, the activation of Bax and Bak induces pore formation at the outer mitochondrial membrane. The resulting membrane permeabilization favors the cytoplasmic release of apoptogenic factors, including cytochrome $c$. The latter interacts with the adapter Apaf-1 which enables the initiator caspase- 9 to be activated. In turn, caspases- 8 and -9 trigger the activation of effector caspases. These proteases can be inactivated by endogenous inhibitors of apoptosis protein (IAP). The IAP antagonist Second mitochondria-derived activator of caspases (Smac) is one of the apoptogenic factors released from the mitochondria [3]. Furthermore, several signaling pathways are known to interfere indirectly with apoptosis: these include the nuclear factor-kappaB (NF-kB) pathway, which activates the transcription of antiapoptotic proteins (such as Mcl-1 and IAPs) or the phosphatidylinositol-3kinase (PI3K)/AKT pathway that phosphorylates several 
protein targets of relevance to apoptosis (such as Bad) [4]. Both pathways may thus downregulate caspase-dependent apoptosis. In contrast, the p53 pathway is an integrator of cellular stress and is capable of stimulating apoptosis notably through transcriptional activation of proapoptotic proteins (e.g., Puma and Noxa).

\subsection{Defective apoptosis in CLL}

Chronic lymphocytic leukemia results from the clonal expansion of a CD5-positive subpopulation of B lymphocytes which progressively accumulate in the bone marrow, lymph nodes and peripheral blood. Although proliferative pools in the bone marrow and lymph nodes probably feed the blood compartment, the leukemic cells in the blood are quiescent but are unable to initiate their apoptotic program. This situation is due to several factors including defects in the CLL cells' apoptotic machinery and excessive survival signals delivered by the microenvironment [5-9]. Bone marrow stroma cells, nurse-like cells and $\mathrm{T}$ cells produce chemokines and cytokines that activate survival pathways such as NF-kB or PI3K/AKT. Indeed, these pathways are constitutively activated in CLL cells and this leads to the transcription and overexpression of key antiapoptotic proteins (notably several members of the Bcl-2 and IAP families). X-linked IAP (XIAP) appears to be the IAP that has a major role in caspase inactivation [10]. Regarding the prosurvival Bcl-2 proteins, it is now well established that in addition to Bcl2 itself, Mcl-1 is a crucial player in impaired apoptosis in
CLL cells $[6,7,11,12]$. Indeed, silencing Mcl-1 with small interfering RNA (siRNA) is enough to induce apoptosis in CLL cells [13]. Other signaling pathways are also involved in the overexpression of antiapoptotic proteins in CLL cells: for example, B cell receptor (BCR) signals reportedly upregulate $\mathrm{Mcl}-1$ expression through the PI3K/AKT pathway [8]. Lastly, alterations in apoptosis regulators such as p53 (which are frequently observed in CLL) may be implicated in the defective apoptosis. A schematic representation of the impaired apoptotic machinery in CLL cells is shown in Figure 1.

\subsection{Chronic lymphocytic leukemia is an incurable disease}

The treatment of CLL patients with combinations of alkylating agents, purine analogues and monoclonal antibodies (fludarabine, cyclophosphamide and rituximab or allied agents) has significantly increased both the proportion and duration of complete remissions, and prolonged the overall survival $[14,15]$. Nevertheless, the treatment failure rate is still high and most treatmentresponsive patients subsequently relapse.

\subsection{Apoptosis-based strategies for CLL}

Various ways of reactivating the apoptotic machinery in primary CLL cells have been developed over the past 15 years as extensively reviewed $[5,8,16]$.

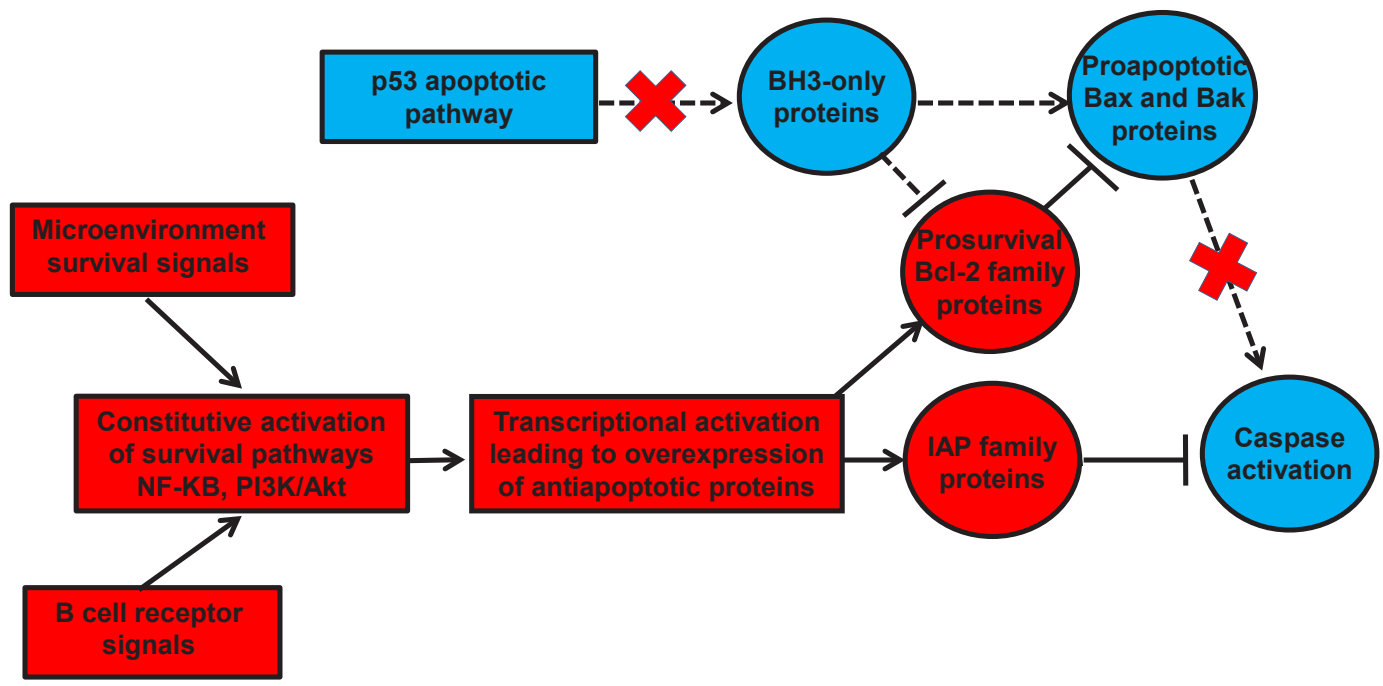

Figure 1: Schematic representation of the impaired mitochondrial caspase-dependent apoptosis in CLL cells. Antiapoptotic factors are colored in red and proapoptotic components are colored in blue. Constitutive activation of survival pathways by microenvironment signals and B cell receptor signaling leads to the transcriptional activation of prosurvival factors from the Bcl-2 and IAP families which are thus overexpressed in CLL cells. The increased antiapoptotic activity exerted by these factors results in (i) sequestration of the proapoptotic proteins Bax and Bak (which thus prevents the mitochondrial membrane permeabilization and the subsequent cascade of caspase activation) and (ii) direct inhibition of caspase activities by IAP proteins. Moreover, deficiencies in the p53 apoptotic pathway (which are frequently observed in CLL) reduce the expression of BH3-only proteins like Puma and Noxa (known to block the antiapoptotic activity of prosurvival Bcl-2 family members and promote Bax and Bak activation). IAP, inhibitor of apoptosis protein; NF-kB, nuclear factor-kappaB; PI3K, phosphoinositol-3 kinase. 


\begin{tabular}{|c|c|}
\hline $\begin{array}{l}\text { Table 1: Functiona } \\
\text { inducers in chronic } \\
\text { cells }\end{array}$ & $\begin{array}{l}\text { diversity of apoptosis } \\
\text { lymphocytic leukemia }\end{array}$ \\
\hline $\begin{array}{l}\text { Inhibitors of prosurvival } p \\
\text { families) }\end{array}$ & rotein expression (Bcl-2 and IAP \\
\hline $\begin{array}{l}\text { Cyclin-dependent kinase } \\
\text { inhibitors }\end{array}$ & $\begin{array}{ll}\text { Flavopiridol, } & \text { roscovitine, } \\
\text { dinaciclib, SNS-032 }\end{array}$ \\
\hline Translational inhibitors & Homoharringtonine, silvestrol \\
\hline Small interfering RNA & Mcl-1 siRNA \\
\hline Antisense oligonucleotides & Oblimersen \\
\hline Inhibitors of prosurvival p & rotein activity \\
\hline BH3 mimetics & $\begin{array}{l}\text { ABT series, AT-101, ApoG2, } \\
\text { obatoclax, 072RB }\end{array}$ \\
\hline SMAC mimetics & XIAP antagonist \\
\hline Enhancers of proapoptotic & protein expression \\
\hline Proteasome inhibitors & $\begin{array}{l}\text { Bortezomib, lactacystin, MG- } \\
132 \text {, carfilzomib }\end{array}$ \\
\hline $\begin{array}{l}\text { Plant-derived proteasome } \\
\text { inhibitors }\end{array}$ & $\begin{array}{l}\text { EGCG, quercetin, apigenin, } \\
\text { xanthohumol }\end{array}$ \\
\hline $\begin{array}{ll}\text { Histone deacetylase } & \\
\text { inhibitors } & \end{array}$ & $\begin{array}{l}\text { Depsipetide, valproic acid, } \\
\text { MGCD0103, vorinostat }\end{array}$ \\
\hline Activators of apoptotic pat & hways \\
\hline p53 activators & Nutlin-3a, PARP inhibitor \\
\hline $\begin{array}{l}\text { Death receptor pathway } \\
\text { activators }\end{array}$ & TRAIL \\
\hline Inhibitors of survival path & ways \\
\hline \begin{tabular}{ll|} 
Nuclear & factor-kB \\
inhibitors & \\
\end{tabular} & BAY-117082 \\
\hline $\begin{array}{l}\text { Phosphoinositol-3 kinase/ } \\
\text { AKT inhibitors }\end{array}$ & CAL-101, Akt-1/2 \\
\hline $\begin{array}{ll}\text { Inhibitors of } \\
\text { microenvironment signals }\end{array}$ & $\begin{array}{l}\text { Lenalidomide, plerixafor (anti- } \\
\text { CXCR4) }\end{array}$ \\
\hline Modulators of other signal & ing pathways \\
\hline $\begin{array}{l}\text { B cell receptor signaling } \\
\text { inhibitors }\end{array}$ & $\begin{array}{l}\begin{array}{l}\text { Fostamatinib } \\
\text { (Lyn kinase) }\end{array} \\
\end{array}$ \\
\hline Kinase inhibitors & $\begin{array}{l}\text { Sorafenib (multi-kinases), } \\
\text { imatinib (Abl kinase) }\end{array}$ \\
\hline JNK activators & Fenretinide \\
\hline Others & \\
\hline $\begin{array}{l}\text { Anticancer drugs and other } \\
\text { therapeutics }\end{array}$ & $\begin{array}{l}\text { Fludarabine, vinblastine, } \\
\text { acadesine, bendamustine }\end{array}$ \\
\hline $\begin{array}{l}\text { Hormones and anti- } \\
\text { inflammatory agents }\end{array}$ & Corticoids, aspirin \\
\hline Cytokines & Interleukin-21 \\
\hline Hsp90 inhibitors & 17-DMAG \\
\hline Multi-target compounds & $\begin{array}{l}\text { Resveratrol, curcumin and } \\
\text { other polyphenols, triterpens, } \\
\text { xanthones, hyperforin }\end{array}$ \\
\hline $\begin{array}{l}\text { SiRNA, small interfering RN } \\
\text { IAP, inhibitor of apoptosis prot } \\
\text { SMAC, second mitochondria-c } \\
\text { poly (ADP-ribose) polymerase. }\end{array}$ & $\begin{array}{l}\text { A; EGCG, epigallocathechin gallate; } \\
\text { ein; BH3, Bcl-2 homology domain } 3 \text {; } \\
\text { derived activator of caspases; PARP, }\end{array}$ \\
\hline
\end{tabular}

These approaches include inhibition of NF-kB or PI3K/ AKT pathways (using for example CAL-101, a PI3Kdelta isoform), enhancement of p53-dependent apoptosis (using nutlin-3a or inhibitors of poly[ADP-ribose] polymerase-1), stimulation of the extrinsic pathway through the death receptors, interference with BCR signaling (using notably dasatinib, a Lyn kinase inhibitor and the Syk inhibitor fostamatinib) or with survival signals delivered by the leukemic microenvironment (particularly lenalidomide that repairs the $\mathrm{T}$ cell immunologic synapse defect, and CXCR4 targeting using plerixafor), novel chemotherapeutics (e.g. bendamustine, forodesine, acadesine) and monoclonal antibodies. However, the most extensively studied approach has been the identification of agents capable of directly triggering the intrinsic mitochondrial pathway of apoptosis. This prompted the discovery of the in vitro apoptosis inducers reviewed in the present article.

\section{APOPTOSIS INDUCERS IN CLL CELLS}

Apoptosis inducers comprise a broad variety of synthetic and natural products as illustrated in Tables 1 and 2. Some of these agents were found to inhibit the expression or activity of antiapoptotic molecules whereas others can upregulate proapoptotic proteins.

\subsection{Inhibitors of antiapoptotic protein expression}

\section{Flavopiridol}

Flavopiridol is a semisynthetic flavone derived from rohitukine (an alkaloid isolated from Indian plants). Its chemical structure is shown in Figure 2. To the best of our knowledge, this flavonoid was the first apoptosis inducer to be identified in CLL cells [17] and is still one of the most potent. Flavopiridol acts by downregulating the antiapoptotic proteins Mcl-1 and XIAP through inhibition of cyclin-dependent kinases (CDK) required for RNA polymerase II activation [18]. Consequently, transcription of many short-lived proteins is decreased resulting in downregulation of key proteins such as Mcl-1, Bcl-xL, several IAP (XIAP, c-IAP-2, survivin), C-Myc (a transcriptional activator of Mcl-1), Mdm-2 (a p53 antagonist) and p21 [19]. Flavopiridol's effects on transcription are therefore not specific but do affect a large number of proteins. It is noteworthy that the decrease in Bcl-2 mRNA does not change Bcl-2 protein levels. The initial clinical trials of various flavopiridol regimens in CLL gave disappointing results, probably because the flavonoid is strongly bound by plasma proteins [20]. More successful outcomes were recorded with a pharmacologically-based dosing schedule in a Phase II trial on refractory and genetically high-risk CLL patients, providing more than $50 \%$ of responses and improvements in progression-free survival [21]. However, dose- 
Table 2: Structural diversity of apoptosis inducers in chronic lymphocytic leukemia cells

\begin{tabular}{|l|l|l|l|}
\hline \multicolumn{2}{|l|}{ Type of compound } & \multicolumn{2}{l|}{ Examples } \\
\hline Plant-derived compounds & Flavonoids & Flavones & \\
\hline & & Flavonols & Qlavopiridol, apigenin \\
\hline & & Flavanols & Epigallocatechin gallate (EGCG) \\
\hline & & Prenylated & Xanthohumol \\
\hline & Stilbenoids & & Resveratrol, combretastatins \\
\hline Vinca alkaloids & Aldehydes & & Gossypol, AT-101 \\
\hline Other alkaloids & Curcuminoids & & Curcumin \\
\hline Phloroglucinols & & & Vinblastine \\
\hline Xanthones & & & Homoharringtonine, silvestrol \\
\hline
\end{tabular}

Other natural products and derivatives

\begin{tabular}{|c|c|c|}
\hline Starfish alkaloid & & Roscovitine/seliciclib \\
\hline Cytokines & & TRAIL, Interleukin-21 \\
\hline Hormones & & Corticoids \\
\hline Small organic molecule $\mathrm{BH} 3$ mimetics & & Obatoclax, Apogossypolone (ApoG2) \\
\hline $\mathrm{BH} 3$ peptide-derived $\mathrm{BH} 3$ mimetics & & 072RB \\
\hline Bacteria-derived products & & Lactacystin, depsipeptide \\
\hline \multicolumn{3}{|l|}{ Synthetic compounds } \\
\hline \multirow[t]{6}{*}{ Chemical inhibitors } & Proteasome & Bortezomib \\
\hline & HDAC & MGCD0103 \\
\hline & CDK & Dinaciclib, SNS-032 \\
\hline & Other kinases & Dasatinib, fostamatinib, sorafenib \\
\hline & Signaling pathways & CAL-101, nutlin-3 \\
\hline & Microenvironment & Lenalidomide, plerixafor \\
\hline Terpenoids & Triterpens & CDDO \\
\hline Small interfering RNA & & Mcl-1 siRNA \\
\hline Antisense oligonucleotides & & Oblimersen (anti-Bcl-2) \\
\hline Anticancer drugs and other therapeutics & & Fludarabine, bendamustine, forodesine \\
\hline Retinoid derivatives & & Fenretinide \\
\hline Synthetic BH3 mimetics & & ABT series \\
\hline
\end{tabular}

BH3, Bcl-2 homology domain 3; HDAC: histone deacetylase; CDK: cyclin-dependent kinase; CDDO: 2-cyano-3,12dioxoolean-1,9-dien-28oic acid. 
escalation is difficult because of the lack of predictive markers for toxicity. Flavopiridol is currently investigated in combination with other agents and as a means of eradicating residual disease after chemotherapy [20].

\section{Other CDK inhibitors}

Other CDK inhibitors are capable of inducing CLL cell apoptosis via the inhibition of Mcl-1 transcription: they include the natural compound roscovitine/seliciclib (a starfish-derived alkaloid) [22] and the synthetic agents SNS-032 and dinaciclib $[23,24]$. The latter two agents are currently in clinical evaluation in CLL. Like flavopiridol, several other plant-derived flavones such as apigenin (Figure 2) are CDK inhibitors that induce apoptosis by transcriptional suppression of Mcl-1 [25]. This property might contribute to apigenin's proapoptotic effects on CLL cells [26], although other mechanisms also play important roles (see below).

\section{Homoharringtonine and silvestrol}

Homoharringtonine (Figure 2) and silvestrol are alkaloids isolated from Asian plants which were originally described as translation inhibitors. Both compounds are able to induce mitochondrial apoptosis in CLL cells by downregulating Mcl-1 [27,28]. Indeed, translational inhibition preferably targets labile proteins. However, a very recent report indicates that inhibition of $\mathrm{Mcl}-1$ translation is not critical for the proapoptotic effects of the compounds and that they act via several different cell death mechanisms [29]. Silvestrol has shown in vivo antileukemic activity in the TCL-1 transgenic mouse model of human CLL [28]. Interestingly, sorafenib (a multikinase inhibitor) induces CLL cell death by translational downregulation of Mcl-1 [30].

\section{Specific inhibitors of Bcl-2 family protein expression}

Whereas CDK inhibitors and translational inhibitors do not selectively target antiapoptotic molecules, specific inhibition of Bcl-2 protein expression can be envisaged because Mcl-1 siRNA is capable of triggering CLL cell apoptosis in vitro [13]. However, technical obstacles currently prevent the RNA interference approach from being applied in the clinic [31]. The clinical development of short hairpin RNA mimicking endogenous microinterfering RNA (miR) appears to be even more difficult to apply [32] whereas the loss of miR-15a1 and miR-16 (targeting notably Bcl-2 and Mcl-1) in CLL was the first event of this type to be discovered [33]. In contrast, the antisense oligonucleotide strategy (targeting mRNA for degradation) has already been tested in the clinic with oblimersen (the most extensively tested Bcl-2 antisense oligonucleotide). Unfortunately, oblimersen has only moderate therapeutic activity in CLL patients even when combined with fludarabine and cyclophosphamide

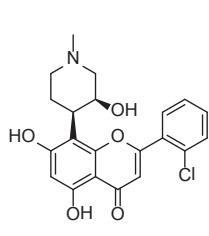

Flavopiridol

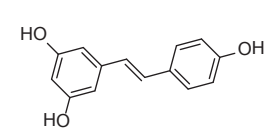

Resveratrol
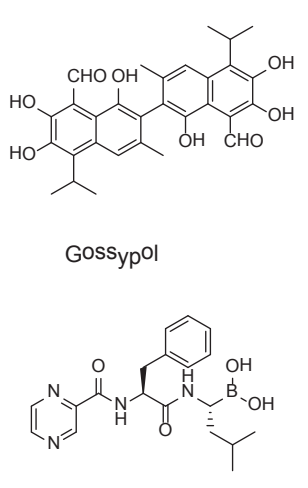

Bortezomib

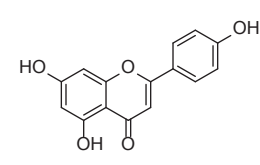

Apigenin

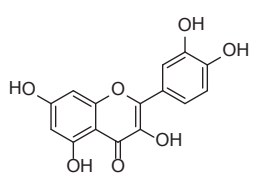

Quercetin

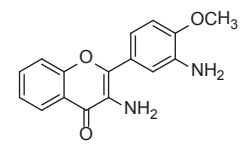

3.3'-Diamino-4'-methoxyflavone

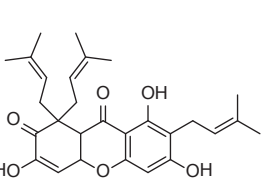

Allanxanthone C
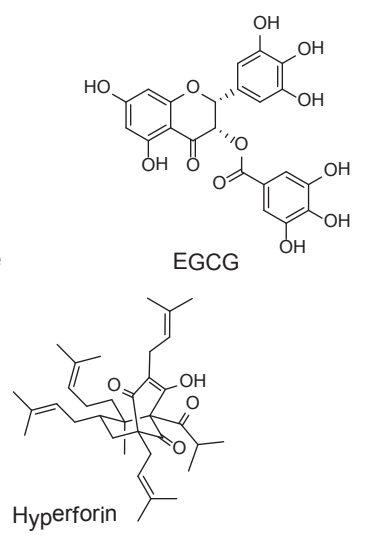

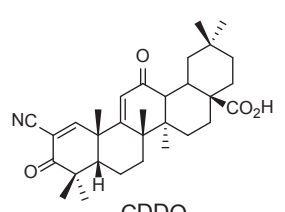

CDDO

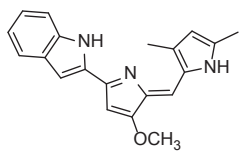

Obatoclax (GX-070)

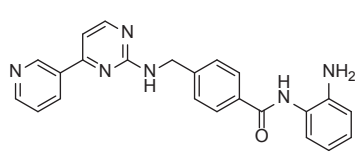

MGCD-0103

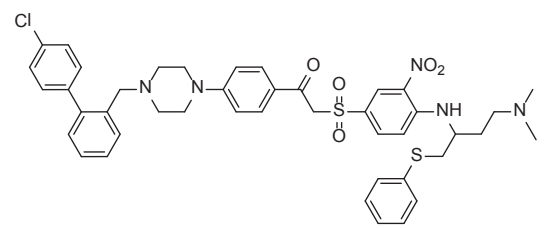

ABT - 737

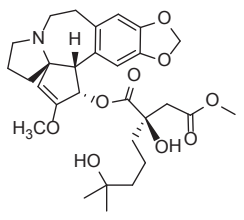

Homoharringtonine

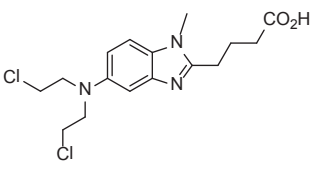

Bendamustine

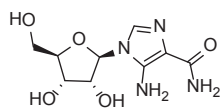

AICA-riboside

Figure 2: Chemical structures of some apoptosis inducers in CLL. EGCG, epigallocatechin gallate; CDDO, 2-cyano-3,12dioxoolean-1,9-dien-28oic acid. 


\begin{tabular}{l} 
Table 3: Pathways other than the intrinsic \\
mitonchondrial pathway used by apoptosis \\
inducers in chronic lymphocytic leukemia \\
cells \\
\hline Cell death pathways \\
\hline Extrinsic cell death receptor pathway \\
\hline Endoplasmic reticulum stress response \\
\hline Reactive oxygen species (ROS) generation \\
\hline Caspase-independent apoptosis \\
\hline Autophagic cell death \\
\hline p53 pathway \\
\hline Survival pathways \\
\hline Nuclear factor-kappaB (NF-kB) \\
\hline Phosphatidylinositol-3 kinase (PI3K) \\
\hline Protein kinase B (AKT) \\
\hline Mammalian target of rapamycin (mTOR) \\
\hline Other signaling pathways \\
\hline B cell receptor \\
\hline Hsp90 \\
\hline Jun N-terminal kinase (JNK) \\
\hline Mitogen activated protein (MAP) kinase \\
\hline
\end{tabular}

[34]. This poor result was attributed to off-targets effects and so attempts to overcome the latter have been proposed recently [35].

\subsection{Inhibitors of the functional activity of prosurvival Bcl-2 proteins}

The BH3 mimetic concept prompts the development of small molecules capable of mimicking the BH3only proteins which are natural, direct antagonists of the prosurvival Bcl-2 proteins. These small molecules are designed to bind to the prosurvival proteins (with the same high affinity as the natural ligands), inhibit the antiapoptotic activity of the latter (by releasing the sequestered proapoptotic Bax and Bak) and thus induce apoptosis [36]. The generated $\mathrm{BH} 3$ mimetics are either short peptides modeled on $\mathrm{BH} 3$ domains or small organic molecules (identified by screening natural product libraries or in silico-designed compounds for their ability to bind Bcl-2 proteins). However, many compounds thus identified did not fully meet the two main criteria defining an authentic BH3 mimetic, i.e. (i) high-affinity binding to the targets and (ii) induction of Bax and Bak-dependent apoptosis [36]. Indeed, these putative $\mathrm{BH} 3$ mimetics were found to act at least partly through off-target effects, such as the generation of reactive oxygen species (ROS), endoplasmic reticulum stress, induction of the $\mathrm{BH} 3$-only
Noxa, caspase-independent or autophagic cell death [3740].

\section{The ABT series}

The organic molecule ABT-737 (Figure 2) targets Bcl-2, Bcl-xL and Bcl-w (but not Mcl-1 or A1) and, for a time, was considered to be the sole bona fide $\mathrm{BH} 3$ mimetic [37]. Initially found to decrease the viability of CLL cells [37], ABT-737 was demonstrated to induce apoptosis through activation of the mitochondrial pathway [41]. Clinical trials have been developed with the orally available version ABT-263 (navitoclax): the recent published Phase I data are promising, with a partial response rate of $35 \%$ in relapsed or refractory CLL patients [42]. To avoid the dose-limiting thrombocytopenia associated with ABT-263 (due to inhibition of Bcl-xL activity), the ABT-199 derivative was designed to bind specifically to $\mathrm{Bcl}-2$. This $\mathrm{BH} 3$ mimetic was found to reduce the tumor burden in the first three CLL patients recruited into an ongoing clinical trial [43].

\section{Obatoclax}

Obatoclax (GX15-070) is a synthetic derivative of natural prodigiosins (Figure 2). It can bind to all prosurvival Bcl-2 proteins albeit with low affinity [44]. This putative pan-BH3 mimetic, whose apoptotic activity has been attributed to various mechanisms (including Noxa induction and inhibition of AKT/mTOR pathway), was found to induce mitochondrial apoptosis in CLL patients' cells [45]. Recent data indicate that obatoclax can directly activate Bax (one of the two executioner molecules in mitochondrial membrane permeabilization) [46]. However, it is not known whether this activity occurs in CLL cells. In Phase I clinical trials, obatoclax have failed to demonstrate significant single agent efficacy in CLL. Ongoing Phase II studies will determine whether obatoclax might be active when combined with other drugs [47].

\section{The gossypol family}

Gossypol is a natural, polyphenolic aldehyde derived from cotton seed (Figure 2) that was already known for its proapoptotic activity prior to the discovery of its putative BH3 mimetic property [48]. Gossypol acts at least partly through off-target mechanisms such as ROS generation, Noxa induction, autophagic cell death $[38,39,49,50]$. It has been shown that gossypol induces mitochondrial apoptosis in CLL cells [51]. The isomer AT-101 proved to be even more active and capable of overcoming stroma-mediated Mcl-1 induction and apoptosis prevention [52]. Phase I/ II trials of AT-101 in CLL have indicated only limited single-agent therapeutic efficacy [36,53]. Several gossypol derivatives (acting predominantly through $\mathrm{BH} 3$ mimicry) are currently in preclinical studies [48]; these include apogossypolone (ApoG2) which was recently reported to induce apoptosis in CLL cells [54]. 


\section{Compound 072RB}

The peptide 072RB derived from the $\mathrm{BH} 3$ domain of Bim is another putative pan-BH3 mimetic that can induce CLL cell apoptosis and this effect is associated with Bcl-xL and Mcl-1 downregulation [55].

\subsection{Upregulators of proapoptotic Bcl-2 proteins}

\section{Histone deacetylase inhibitors}

Histone deacetylation is an epigenetic mechanism for transcriptional repression. Histone deacetylases (HDAC) are overexpressed in many cancers including CLL, in which they mediate epigenetic silencing of miR15a, miR-16 and miR-29b [56]. A number of natural and synthetic HDAC inhibitors (HDACi) such as depsipeptide, vorinostat, LBH589, and MGCD0103 (see Figure 2) can promote different types of cell death in CLL cells notably extrinsic death receptor and intrinsic mitochondrial apoptosis [57-59]. Although ROS generation has been implicated in HDACi-induced apoptosis, it was reported that some HDACi act through transcriptional upregulation of Noxa and Bim mRNA [58]. Clinical data on HDACi in CLL were disappointing: depsipeptide and MGCD0103 have shown strong adverse effects and/or limited therapeutic benefit for patients $[60,61]$. This may be related to the fact that HDACi upregulate not only proapoptotic proteins but also Mcl-1 (mRNA and protein) in CLL cells [62]. Combinations with other drugs are currently under clinical evaluation.

\section{Proteasome inhibitors}

The proteasome complex catalyses the degradation of proteins targeted by ubiquitin and represents the major regulatory pathway in protein turnover [63]. Various classes of chemically distinct proteasome inhibitors have been characterized. They include both synthetic compounds such as the prototype bortezomib (Figure 2) and natural products such as lactacystin and epoxomicin. These compounds are found to affect key regulatory cellular processes and have antitumor functions by inducing apoptosis. Proteasome inhibitors enhance the stability of many proteins and cause their accumulation.

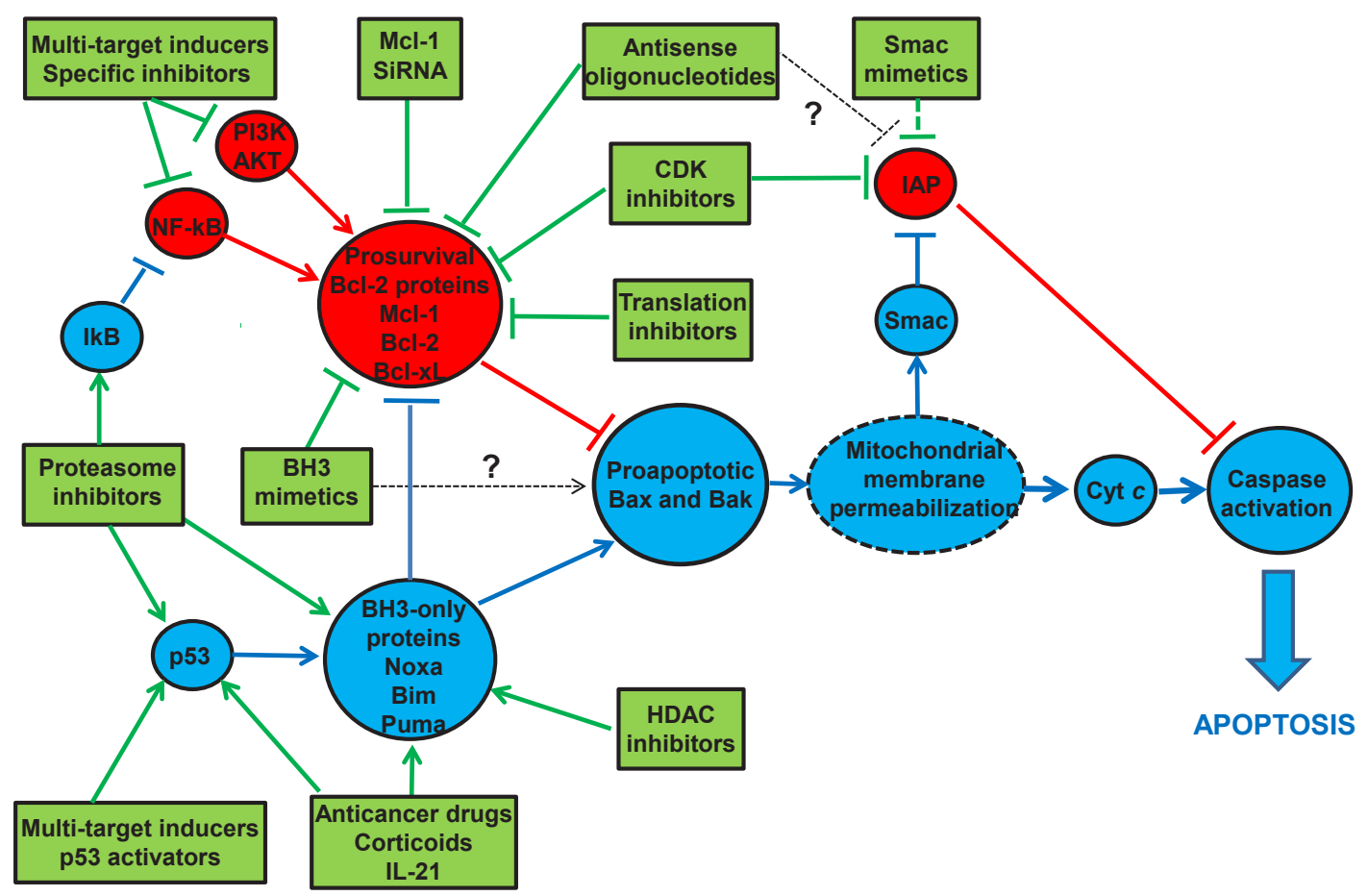

Figure 3: Mechanisms of action of apoptosis inducers that activate the mitochondrial caspase-dependent pathway in CLL cells. Apoptosis inducers can either inhibit antiapoptotic proteins or stimulate proapoptotic proteins. Their main targets are Bcl-2 family members. In the former mechanism, several types of compounds downregulate the expression of prosurvival Bcl-2 proteins whereas BH3 mimetics inhibit their activity (via sequestration of Bax and Bak, the executioner molecules in the mitochondrial membrane permeabilization). In the latter mechanism, apoptosis inducers upregulate the expression of BH3-only proteins (the endogenous antagonistic ligands for prosurvival Bcl-2 proteins, some of which are able to activate Bax and Bak directly). Inhibition of antiapoptotic factors and stimulation of proapoptotic proteins can also be achieved indirectly by some compounds including multi-targets apoptosis inducers, which are capable of interfering with various signaling pathways (e.g., NF-kB, PI3K/AKT, p53). Inhibition of other antiapoptotic proteins such as IAP (antagonizinz caspase activity) is not sufficient to trigger apoptosis but does amplify the effects of certain apoptosis inducers. Blue circles: proapoptotic factors; red circles: antiapoptotic molecules; green boxes: apoptotic inducers. NF-kB, nuclear factor-kappaB; PI3K, phosphoinositol-3 kinase; SiRNA, small interfering RNA; CDK, cyclin-dependent kinase; HDAC, histone deacetylase; IL-21, interleukin-21; IAP, inhibitor of apoptosis protein; Cyt c, cytochrome c; Smac, second mitochondria-derived activator of caspases. 
It is well established that two targets are IkBalpha (the physiologic inhibitor of NF-kB, which governs the induction of a number of antiapoptotic proteins) and the tumor suppressor p53 (which is known to activate the transcription of proapoptotic proteins). Two other targets, the BH3-only proteins Bim and Noxa, are increasingly thought to be crucial for the proteasome inhibitors' proapoptotic mechanisms of action [64].

More than a decade ago, the proteasome inhibitors lactacystin and MG-132 were found to be potent inducers of caspase-dependent mitochondrial apoptosis in CLL cells [65]. Bortezomib (which has been approved for the treatment of multiple myeloma and mantle cell lymphoma) also induces apoptosis in CLL cells by enhancing the stability and eliciting the accumulation of the BH3-only protein Noxa [66]. However, a clinical trial of bortezomib in CLL evidenced several toxic side-effects and failed to produce objective responses [67]. These disappointing results may well be related to the fact that bortezomib and other proteasome inhibitors (e.g. MG132 and epoxomicin) also induce Mcl-1 accumulation notably in CLL cells: this would decrease the proteasome inhibitors' apoptotic response and thus therapeutic efficacy [68]. Interestingly, carfilzomib (a second-generation proteasome inhibitor) shows activity in CLL cells through an atypical mechanism, which has prompted the initiation of a Phase I clinical study [69]. However, carfilzomib also promotes Mcl-1 upregulation [70]. Combinations of certain proteasome inhibitors with other drugs are tested in ongoing clinical trials.

\section{Plant-derived proteasome inhibitors}

A variety of compounds present in fruits, vegetables and other plants can inhibit proteasome activities $[63,71]$. They include polyphenols such as resveratrol and curcumin, flavonoids (also belonging to the wide class of polyphenols) such as the flavone apigenin, the flavonol quercetin and the catechin epigallocatechin gallate (EGCG) as well as alkaloids of the terpenoid family such as the triterpen celastrol [72]. All these natural proteasome inhibitors display proapoptotic properties [71-73]. It is noteworthy that resveratrol, curcumin, apigenin, quercetin and EGCG induce CLL cell apoptosis (see below) as does the synthetic diaminomethoxyflavone [74] that we have recently shown to be a proteasome inhibitor [75]. It is therefore possible that these compounds activate CLL cell apoptosis at least partly through the inhibition of proteasomal degradation.

\section{Hyperforin}

Hyperforin is a phloroglucinol purified from the plant St John's wort (Figure 2). It has multiple biological properties, including in vitro and in vivo antitumor effects which are associated in some cases with apoptosis induction [76]. We were the first to show that hyperforin triggers caspase-dependent mitochondrial apoptosis in primary CLL cells [77]. This natural phloroglucinol acts through upregulation of the $\mathrm{BH} 3$-only protein Noxa, possibly via inhibition of proteasomal activity $[78,79]$. Interestingly, hyperforin-induced Noxa upregulation occurs without change in Mcl-1 expression [79].

\section{Drugs that upregulate $\mathrm{BH} 3-0 n l y$ proteins in CLL}

Although DNA-damaging chemotherapy is thought to kill tumor cells mainly through the p53 pathway, the mechanisms involved have still not been unambiguously defined. A recent study demonstrated that the anticancer effect of cyclophosphamide in a transgenic mouse model of lymphoma requires not only the BH3-only proteins Puma and Noxa (which are p53 targets) but also the p53independent Bim [80]. Whereas Puma strictly depends on p53, Noxa can also be regulated independently of p53. Many drugs used to treat CLL patients can trigger apoptosis in vitro; interestingly, this effect is associated with induction of at least one of the three proapoptotic BH3-only proteins mentioned above. Fludarabine can induce upregulation of Puma mRNA expression [81], and glucocorticoids trigger caspase-dependent apoptosis by increasing Bim mRNA levels [82]. Cisplatinium acts by Noxa upregulation as a result of ROS generation [83]. The purine nucleoside AICA-riboside (also called acadesine, see Figure 2) induces mitochondrial apoptosis of CLL cells via p53-independent increases in Noxa and Bim mRNA levels [84]. Acadesine is currently being evaluated in a Phase I/II trial in CLL. The purine analog and alkylating agent bendamustine (Figure 2) activates the mitochondrial apoptotic pathway by upregulating Puma and Noxa. Unlike Puma, the Noxa upregulation seems to result from ROS generation; bendamustine also induces caspase-independent cell death [85].

\section{Other CLL cell apoptosis inducers upregulating BH3- only proteins}

Aspirin was originally found to induce caspasedependent apoptosis in CLL cells and this effect was recently associated with Noxa upregulation [86]. The synthetic phenylacetylenesulfonamide (PAS, also refered to as pifithrin-mu) exerts similar effects via a p53-independent increase in Noxa mRNA levels [87]. Another CLL cell apoptosis inducer, forodesine (a purine nucleoside phosphorylase inhibitor), can modulate a number of apoptosis proteins and stimulate Bim protein expression [88]. A pharmacodynamic study of oral forodesine has shown its biological activity in CLL patients [89].

\subsection{Other natural CLL cell apoptosis inducers}

\section{Resveratrol, other grape-derived polyphenols and derivatives}

Trans-resveratrol is a phytoalexin from the stilbene family of polyphenols (Figure 2) which is present in 
numerous plants, fruits and vine products. This compound was already known to protect against cardiovascular diseases. Extensive in vitro studies have revealed that resveratrol also displays potential anticancer properties. The polyphenol regulates many different molecular targets and signaling pathways [90]. These include p53, AP-1, members of the IAP and Bcl-2 families (such as Puma, Bim and Noxa), proteasome activity, ROS production, NF-kB, PI3K/AKT, MAP kinase, TRAILdeath receptor and mitochondrial pathways. Resveratrol therefore displays the hallmarks of a multi-target apoptosis inducer. We were the first to report that resveratrol induces apoptosis in primary CLL cells, triggers the mitochondrial pathway and activates caspase-3 [91]. Similar effects have been observed with other wine-derived polyphenols (vineatrols) and an acetate derivative of epsilon-viniferin (a resveratrol dimer) [74,92]

\section{Curcumin}

Curcumin (an active component of turmeric) is another well-known polyphenol with a broad range of biological properties, including the ability to induce apoptosis in CLL cells [93]. Although it was originally suggested that curcumin acts through NF-kB inhibition, the polyphenol also inhibits proteasome activity, AKT and other signaling pathways (e.g. STAT3), downregulates Mcl-1 and XIAP and upregulates Bim [93].

\section{Epigallocatechin gallate}

This catechin (or flavanol) is the most active flavonoid in green tea (Figure 2). Epigallocatechin gallate (EGCG) has pleiotropic effects. It can notably trigger caspase-dependent mitochondrial apoptosis in many tumor models, including primary CLL cells in which it downregulates Mcl-1 and XIAP [94]. Several other crucial apoptotic pathways such as proteasome inhibition are involved in EGCG's mechanisms of action [73]. A Phase II study of EGCG in CLL has shown promising results with reduction in lymphocytosis and/or adenopathy in 29 out of 42 patients $(69 \%)$ [95].

\section{Quercetin}

Like EGCG, this tea-derived flavonol (Figure 2 ) is a multi-target apoptosis inducer and proteasome inhibitor [71]. Quercetin can trigger both the extrinsic and intrinsic pathways in primary CLL cells, notably by Mcl-1 downregulation; the mechanism involves inhibition of the PI3K/AKT pathway, which in turn leads to the instability Mcl-1 mRNA and protein [96,97].

\section{Apigenin and diaminomethoxyflavone}

The natural flavone apigenin (Figure 2) has proapoptotic activity in CLL cells, and this effect has been associated with decreased AKT phosphorylation and inhibition of the PI3K/AKT pathway [26]. Given that apigenin is known to inhibit both proteasome and CDK activities [25,71] and to target several apoptotic pathways [98], the compound may act through several mechanisms in CLL cells. As mentioned above, diaminomethoxyflavone is an apoptosis inducer in CLL cells [74] and this synthetic flavone can also inhibit the $\mathrm{PI} 3 \mathrm{~K} / \mathrm{AKT}$ pathway and proteasome activity [75].

\section{Xanthohumol}

This plant-derived, prenylated flavonoid is able to induce CLL cell death through caspase-dependent apoptosis resulting from activation of endoplasmic reticulum stress [99]. In the same study, xanthohumol was found to inhibit both proteasome activity and Mcl1 expression and these effects were associated with inhibition of the translation initiator factor eIF2alpha but not the modulation of NF-kB activation. Hence, xanthohumol appears to be a natural proteasome inhibitor capable of downregulating Mcl-1 in CLL cells.

\section{Triterpenoids}

Natural and synthetic triterpenoids are potential antitumor compounds possessing multifunctional properties including antiproliferative, antiangiogenic, antiinflammatory and proapoptotic activities. The synthetic triterpenoid 2-cyano-3,12-dioxoolean-1,9-dien-28oic acid (CDDO, see Figure 2) was shown to elicit apoptosis via the mitochondrial pathway in CLL cells [100] and exert antileukemic effects in a transgenic mouse model of CLL [101]. Unlike the natural triterpen celastrol, CDDO is not a proteasome inhibitor but reportedly acts through various mechanisms, including inhibition of the NF-kB pathway, endoplasmic reticulum stress, death receptor and mitochondrial pathways.

\section{Xanthones}

Xanthones were originally isolated from the tropical fruit mangosteen. They are known to possess a wide spectrum of pharmacological properties and anticancer effects. The compounds do modulate various targets and signaling pathways (including apoptosis pathways) [102]. We have shown for the first time that several xanthones purified from African trees (e.g. allanxanthone C, shown in Figure 2) can induce caspase-dependent apoptosis in CLL cells via activation of the mitochondrial pathway or other mechanisms [103]. We further reported that allanxanthone $\mathrm{C}$ and macluraxanthone have in vivo therapeutic effects in a xenograft murine model of CLL [104].

\section{Arylcoumarin analogs of combretastatins}

Combretastatins are natural stilbenoid polyphenols isolated from African trees. They have antimitotic properties by binding to tubulin, inhibiting its polymerization and thus blocking microtubule assembly. It was reported that the mitotic catastrophe triggered by some combretastatins in human leukemia cells is associated with caspase-dependent apoptosis [105]. We have shown that arylcoumarin derivatives, analogs of combretastatin-A4 (that were synthesized to avoid 
isomerization into the inactive trans-configuration) can induce the caspase-dependent mitochondrial pathway of apoptosis in CLL cells [106].

\section{Vinblastine}

The mitotic spindle poison vinblastine was the first vinca alkaloid used in the treatment of CLL. It was recently shown that vinblastine induces acute apoptosis in CLL cells (independently of cell cycle) and that this effect is associated with an increase in Noxa transcripts [107]. Other microtubule-disrupting agents (combretastatin-A4, vincristine and vinorelbine) have the same effects [107].

\subsection{Other types of CLL apoptosis inducers}

\section{Fenretinide}

The synthetic retinoid N-(4-hydroxyphenyl) retinamide (called fenretinide) promotes the intrinsic apoptotic pathway in CLL cells via ROS generation. This is accompanied by $\mathrm{Mcl}-1$ protein degradation resulting from jun N-terminal kinase (JNK) activation [108]. Two other mechanisms have been suggested: inactivation of NF-kB and upregulation of Noxa (which is known to target Mcl-1 for proteasomal degradation).

\section{IAP antagonists}

Two strategies to antagonize caspase inhibitors of the IAP family have been developed [109]. Firstly, small molecules mimicking Smac (the physiological antagonist of IAP proteins) were designed: a Smac mimetic antagonizing XIAP was found to enhance TRAIL-induced CLL cell apoptosis [10]. Secondly, the antisense strategy has been tested in a clinical trial of an XIAP antisense oligonucleotide (AEG35156) in CLL, but the results were not encouraging.

\section{Inhibitors of various kinases and signaling pathways}

A number of agents are currently tested in clinical trials on the basis of their ability to indirectly induce CLL cell apoptosis $[5,8,16]$. This is the case for CAL101 (PI3K inhibitor), Akti-1/2 and A-443654 (AKT inhibitors), BAY117082 (NF-kB inhibitor), inhibitors of kinases involved in BCR signaling such as dasatinib (Lyn kinase) or fostamatinib (Syk) and other kinase inhibitors such as sorafenib (multikinase) or imatinib (c-Abl kinase). Furthermore, activated heat-shock protein 90 (Hsp90) is a chaperone molecule for the zeta-associated protein ZAP-70 which positively regulates BCR signaling and is expressed by CLL cells from patients with aggressive disease. Inhibitors of Hsp90 (e.g. 17-DMAG) induce ZAP70 degradation and apoptosis of CLL cells and are tested in ongoing clinical trials in CLL.

\section{Interleukin-21 (IL-21)}

This cytokine has been reported to mediate CLL cell death through upregulation of the $\mathrm{BH} 3$-only protein Bim
[110].

\section{COMMENTS AND DISCUSSION}

\subsection{The structural and functional diversity of CLL cell apoptosis inducers}

Inducers of CLL cell apoptosis display broad functional diversity (Table 1). The class encompasses inhibitors of transcription (CDK inhibitors), translation, proteasome activity (affecting protein turnover), HDACs (affecting epigenetic regulation), various kinases (affecting different signaling pathways) and the antiapoptotic activity of $\mathrm{Bcl}-2$ proteins (BH3 mimetics). They also include transcription modulators, cytokines, corticoids and various types of cancer drugs (nucleotide analogs, alkylating agents and microtubule-disrupting agents).

Apoptosis inducers also display structural diversity (Table 2). Many are natural compounds (generally derived from plants) or their semisynthetic/synthetic derivatives. This group includes some of the most active compounds such as the prototypic flavopiridol. Although many plant-derived apoptosis inducers are flavonoids (flavones, EGCG, quercetin, xanthohumol) or other types of polyphenols (gossypol, resveratrol, curcumin), other families are also represented, such as xanthones, phloroglucinols (hyperforin) and various alkaloids (homoharringtonine, silvestrol). Some apoptosis inducers are derived from bacteria (depsipetide, lactacystin). Furthermore, certain cancer drugs (vinblastine for example) are themselves of natural origin. There are also many synthetic apoptosis inducers including $\mathrm{BH} 3$ mimetics (the ABT series), triterpens (CDDO), various enzyme inhibitors (proteasome, HDACs, kinases and survival pathways), antisense oligonucleotides and cytostatic drugs.

\subsection{The mechanisms of action of apoptosis inducers}

As appears from the data, apoptosis inducers act via two major mechanisms: (i) inhibition of either the expression or activity of antiapoptotic proteins and (ii) upregulation of proapoptotic molecules (Figure 3). The targets are mostly Bcl-2 family proteins; this may involve either downregulation of the family's prosurvival members (mainly Bcl-2 and Mcl-1), which are crucial players in the impaired apoptosis in CLL, or upregulation the BH3-only proteins (Bim, Puma, Noxa), which are functional antagonists of the prosurvival members. These data have therefore validated the Bcl-2 family proteins to be crucial targets for novel therapeutic strategies, which prompted the development of $\mathrm{BH} 3$ mimetics. Regarding the inhibition of IAP family proteins, it seems to require 
TRAIL-activation of the death receptor pathway for the full induction of apoptosis. Apoptosis inducers can also act indirectly through either inactivation of $\mathrm{NF}-\mathrm{kB}$ or PI3K/AKT survival pathways (which are responsible for transcriptional activation of $\mathrm{Bcl}-2$ and IAP proteins) or stimulation of the proapoptotic p53 pathway (resulting in induction of BH3-only proteins). Lastly, some multitarget apoptosis inducers (such as resveratrol, curcumin, flavonoids, xanthones, hyperforin and triterpens) are capable of acting through several of these pathways (NF$\mathrm{kB}, \mathrm{PI} 3 \mathrm{~K} / \mathrm{AKT}$ and p53). Most of these compounds are natural proteasome inhibitors.

The fact that many apoptosis inducers directly target Bcl-2 family proteins constitutes a theoretical advantage over chemotherapeutic agents, since these proteins regulate the initial molecular events responsible for triggering the caspase-dependent mitochondrial apoptotic pathway. Indeed, apoptosis inducers have mostly been found to trigger mitochondrial membrane permeabilization, cytochrome $c$ release and the caspase cascade. Nevertheless, apoptosis inducers can also use other mechanisms: caspase activation can result from endoplasmic reticulum stress, ROS generation or the death receptor pathway, and some compounds can even trigger caspase-independent apoptosis or autophagic cell death (Table 3).

\subsection{On the clinical use of apoptotic inducers in CLL}

The most encouraging clinical data have been obtained with flavopiridol (the semisynthetic CDK inhibitor that decreases Mcl-1 transcription) and ABT263 (the BH3 mimetic that antagonizes the activity of prosurvival Bcl-2 proteins). Promising results were also observed recently with the natural flavonoid EGCG, which inhibits both the proteasome and Mcl-1 expression. Extensive ongoing trials are assessing other CDK inhibitors (SNS-032, dinaciclib), other BH3 mimetics (the new ABT-199, gossypol derivatives), translation inhibitors (homoharringtonine), sorafenib and other kinase inhibitors, bendamustine, forodesine, acadesine and Hsp90 inhibitors. Some synthetic apoptosis inducers with high potency in vitro have turned out to be disappointing when used to treat CLL patients: this is the case of the proteasome inhibitor bortezomib, several HDAC inhibitors (MGCD0103 for instance) and antisense oligonucleotides (targeting Bcl-2 or XIAP). Likewise, the BH3 mimetics obatoclax and AT-101 have not shown therapeutic benefits in CLL. Apoptosis inducers might be more successful in the clinic when rationally combined with conventional chemo-immunotherapy. Hence, flavopiridol, obatoclax, proteasome inhibitors and HDAC inhibitors are currently being tested in combination with other drugs. The triterpen CDDO has not yet been evaluated in CLL patients despite its marked therapeutic effects in a transgenic mouse model of CLL.

Only a few natural apoptotic inducers have been clinically evaluated in CLL. Some plant-derived compounds deserve to be tested in the clinic such as hyperforin. Indeed, the latter advantageously upregulates expression of the proapoptotic protein Noxa but not that of the antiapoptotic Mcl-1 (as compared to bortezomib and HDAC inhibitors which upregulate both of these proteins). Several improved derivatives of hyperforin such as aristoforin have shown innocuousness and efficacy in animal models [76]. Allanxanthone B and macluraxanthone also appear to have therapeutic potential since they were found to exhibit antileukemic effects in a xenograft mouse model of CLL [104]. Lastly, it would be interesting to evaluate natural flavonoids such as apigenin (which inhibits both the proteasome and CDKs) and other plant-derived proteasome inhibitors also capable of Mcl-1 downregulation (e.g. quercetin).

However, the main concern with natural apoptosis inducers is that they often affect multiple molecular targets and signaling pathways; this is the case for resveratrol, curcumin, xanthones and hyperforin, for instance. It is therefore difficult to determine which mechanism is responsible for the proapoptotic effects. Moreover, this pleiotropy may result in adverse drug reaction especially during dose escalation. It is noteworthy that this shortcoming also applies to synthetic apoptosis inducers that are not specific for a unique molecular target (e.g. $\mathrm{CDK}$, proteasome and HDAC inhibitors). Likewise, a survival pathway inhibitor usually affects several other signaling pathways. This is even a problem with $\mathrm{BH} 3$ mimetics: (i) most putative mimetics act through offtarget effects and (ii) the bona fide $\mathrm{BH} 3$ mimetic $\mathrm{ABT}$ 263 antagonizes both Bcl-2 and Bcl-xL, so that inhibition of Bcl-xL activity results in toxic thrombocytopenia in patients. In contrast, the newly developed ABT-199 antagonizes Bcl-2 but not Bcl-xL. All these data support the rational use of apoptosis inducers in combination therapy protocols. Furthermore, it is not surprising that BH3 mimetics such as ABT-737/263 and Bcl-2 antagonists in general also have antiangiogenic properties [111] since Bcl-2 is known to have proangiogenic activities. This may be of value inasmuch as (i) CLL cells constitutively secrete the angiogenic factors VEGF and bFGF and (ii) neo-angiogenesis is an important problem in CLL. Nevertheless, the characterization of apoptosis inducers and their mechanisms of action have enabled the identification of specific molecular targets with potential therapeutic interest as discussed below. 


\subsection{The Noxa/Mcl-1 axis as a critical drug target for apoptosis-based strategies}

A number of apoptosis inducers that upregulate Noxa in CLL cells have been mentioned above: bortezomib and other proteasome inhibitors, several HDAC inhibitors, hyperforin, acadesine, bendamustine, cisplatinium, vinblastine and other vinca alkaloids, PAS and aspirin. Noxa upregulation was also found to be associated with apoptosis elicited by some agents whose proapoptotic effects on CLL cells have been described elsewhere (e.g. obatoclax, gossypol and derivatives and resveratrol). Furthermore, several compounds known for their proapoptotic activities on tumor cells other than CLL are capable of activating Noxa: this is the case for tetramethoxystilbene (a resveratrol analog), isoliquiritigenin (a plant-derived flavonoid), phenoxodiol (a semisynthetic isoflavone) as well as celastrol (a triterpen proteasome inhibitor) [112-115]. Lastly, it must be borne in mind that Noxa can be upregulated by the inhibition of proteasomal activities and that some flavonoids capable of inducing apoptosis in CLL cells have also been characterized as natural proteasome inhibitors (EGCG, quercetin, apigenin). Given that Noxa can bind to Mcl-1 but not other survival Bcl-2 proteins and that Mcl-1 clearly has a critical antiapoptotic role, the Noxa/Mcl-1 axis is an attractive target for apoptosis-based strategies in CLL [116,117].

\subsection{Novel developments in apoptosis-targeted anti-CLL therapies}

A number of reports have suggested combining flavopiridol or other Mcl-1 downregulators with proteasome or HDAC inhibitors (both of which enhance Noxa and Mcl-1 expression) or ABT-263 (which does not antagonize Mcl-1). It is noteworthy that several flavonoids both downregulates Mcl-1 through various different mechanisms (inhibition of CDKs and transcription, translation and the PI3K/AKT pathway, for example) and inhibits the proteasome in CLL cells: these include xanthohumol, apigenin, EGCG and quercetin. Diaminomethoxyflavone is also an apoptosis inducer in CLL cells that can inhibit the PI3K/AKT pathway and proteasome activity. Since proteasome inhibition is known to result in the stabilization and accumulation of the BH3only protein Noxa, it would be particularly interesting to determine whether some of the natural proteasome inhibitors can effectively enhance Noxa expression in CLL cells. Their chemical structure might then serve as a framework for the design of more efficient derivatives. Likewise, other polyphenols that are multi-target apoptosis inducers in CLL cells (such as resveratrol) are already known to enhance Noxa and inhibit Mcl-1 (notably through NF-kB inhibition). Moreover, Noxa expression (induced by ROS generation, for instance) can lead to proteasomal degradation of Mcl-1; this mechanism has been described for the retinoid derivative fenretinide.

Some flavonoids show a structural resemblance to gossypol (see Figure 2) which is thought to function as a BH3 mimetic. It would therefore be useful to establish whether natural apoptosis inducers other than gossypol are capable of BH3 mimicry. In such a case, their chemical structures might serve as a framework for designing new BH3 mimetics.

The development of BH3 mimetics capable of mimicking Noxa and specifically antagonizing Mcl-1 has also been considered. Proof of concept for Noxa-like BH3 mimetics has been provided by the characterization of two compounds: a variant of the $\mathrm{BH} 3$ domain of Bim (called $\mathrm{Bim}_{\mathrm{S}} 2 \mathrm{~A}$ ) and a stabilized alpha-helix of Bcl-2 domains (SAHB) derived from the BH3 region of Mcl-1 itself (called Mcl-1 SAHB) [50]. Furthermore, a prototypical Mcl-1-specific BH3 mimetic (MIM 1) has recently been identified [118]. This small molecule displaces Mcl1 SAHB from its binding partner Mcl-1 and induces apoptosis through Bax/Bak activation in Mcl-1-dependent leukemia cells. Moreover, the first pan-BH3 mimetic has been discovered: it is a SAHB modeled on the Bim BH3 domain (called Bim SAHB) that (i) targets a broad range of survival Bcl-2 proteins (Bcl-xL, Bcl-w, Mcl-1 and A1), (ii) induces caspase-dependent mitochondrial apoptosis in leukemia/lymphoma cells that are resistant to ABT-737 and (iii) suppresses tumor growth in a mouse model of acute myeloid leukemia [119]. Lastly, the BH3 mimetic concept has been used to design a compound capable of mimicking an "activator" BH3-only protein and this compound has led to the characterization of the direct Bax activator molecule BAM7 [120]. It remains to be seen whether the new BH3 mimetics MIM 1, Bim SAHB and BAM7 are capable of inducing apoptosis in primary CLL cells.

\section{CONCLUSIONS}

Attempts to reactivate the apoptotic machinery in CLL cells in vitro have not yet led to the discovery of novel therapeutics capable of curing CLL. However, a number of the identified apoptosis inducers might be used to improve the treatment of CLL patients via combination with conventional chemo-immunotherapy. Moreover, some natural apoptosis inducers deserve to be tested in the clinic. Others might constitute the framework for designing more efficient derivatives. The major drawback of most apoptosis inducers is that they do not have specific molecular targets. Nevertheless, the characterization of the inducers' mechanisms of action has validated the Bcl-2 family members and the Mcl-1/Noxa axis in particular as potential therapeutic targets in CLL. The BH3 mimetic concept is a potent weapon for circumventing the poor specificity of many apoptosis inducers. The discovery 
of new types of BH3 mimetics (ABT-199, MIM 1, Bim SAHB and BAM7) constitutes a critical step forward in the development of novel, apoptosis-targeting drugs for the treatment of CLL and other cancers.

\section{Conflicts of interest}

"The author has no conflicts of interest to declare."

\section{REFERENCES}

1. Hanahan D, Weinberg RA. Hallmarks of cancer: the next generation. Cell. 2011; 144: 646-674.

2. Fulda S. Tumor resistance to apoptosis. Int J Cancer. 2009; 124: 511-515.

3. Strasser A, Cory S, Adams JM. Deciphering the rules of programmed cell death to improve therapy of cancer and other diseases. EMBO J. 2011; 30:3 667-3687.

4. Reed JC. Apoptosis-targeted therapies for cancer. Cancer Cell. 2003; 3: 17-22.

5. Kolb JP, Kern C, Quiney C, Roman V, Billard C. Reestablishment of a normal apoptotic process as a therapeutic approach in B-CLL. Curr Drug Targets Cardiovasc Hematol Disord. 2003; 3: 261-286.

6. Packham G, Stevenson FK. Bodyguards and assassins: Bcl-2 family proteins and apoptosis control in chronic lymphocytic leukemia. Immunology. 2005; 114: 441-449.

7. Chen L, Balakrishnan K, Gandhi V. Inflammation and survival pathways: chronic lymphocytic leukemia as a model system. Biochem Pharmacol. 2010; 80: 1936-1945.

8. Pleyer L, Egle A, Hartmann TN, Greil R. Molecular and cellular mechanisms of CLL: novel therapeutic approaches. Nat Rev Clin Oncol. 2009; 6: 405-418.

9. Burger JA, Ghia P, Rosenwald A, Caligaris-Cappio F. The microenvironment in mature B-cell malignancies: a target for new treatment strategies. Blood. 2009; 114: 3367-3375.

10. Loeder S, Zenz T, Schnaiter A, Mertens D, Winkler D, Döhner $\mathrm{H}$, et al. A novel paradigm to trigger apoptosis in chronic lymphocytic leukemia. Cancer Res. 2009; 69: 89778986.

11. Pepper C, Lin TT, Pratt G, Hewamana S, Brennan P, Hiller $\mathrm{L}$, et al. Mcl-1 expression has in vitro and in vivo significance in chronic lymphocytic leukemia and is associated with other poor prognostic markers. Blood. 2008; 112: 3807-3817.

12. Awan FT, Kay NE, Davies ME, Wu W, Geyer SM, Leung $\mathrm{N}$, et al. Mcl-1 expression predicts progression-free survival in chronic lymphocytic leukemia patients treated with pentostatin, cyclophosphomide, and rituximab. Blood. 2009; 133: 535-537.

13. Hussain SR, Cheney CM, Johnson AJ, Lin TS, Grever MR, Caligiuri MA, et al. Mcl-1 is a relevant therapeutic target in acute and chronic lymphoid malignancies: Downregulation enhances rituximab-mediated apoptosis and complementdependent cytotoxicity. Clin Cancer Res. 2007; 13: 144150.

14. Tam CS, Keating MJ. Chemoimmunotherapy of chronic lymphocytic leukemia. Nat Rev Clin Oncol. 2010; 7: 521532.

15. Gribben JB, O'Brien S. Update on therapy of chronic lymphocytic leukemia. J Clin Oncol. 2011; 29: 544-550.

16. Veliz M, Pinilla-Ibarz J. Treatment of relapsed or refractory chronic lymphocytic leukemia. Cancer Control. 2012: 19: 37-53.

17. Byrd JC, Shinn C, Waselenko JK, Fuchs EJ, Lehman TA, Nguyen PL, et al. Flavopiridol induces apoptosis in chronic lymphocytic leukemia cells via activation of caspase-3 without evidence of bcl-2 modulation or dependence on functional p53. Blood. 1998; 92: 3804-3816.

18. Chen R, Keating MJ, Gandhi V, Plunkett W. Transcription inhibition by flavopiridol: mechanism of chronic lymphocytic leukemia cell death. Blood. 2005; 106: 25132519.

19. Blagosklonny MV. Flavopiridol, an inhibitor of transcription. Cell Cycle. 2004; 3: 1537-1542.

20. Christian BA, Grever MR, Byrd JC, Lin TS. Flavopiridol in chronic lymphocytic leukemia: a concise review. Clin Lymphoma Myeloma. 2009; 9 (Suppl 3): S179-185.

21. Lin TS, Ruppert AS, Johnson AJ, Fischer B, Heerema NA, Andritsos LA, et al. Phase II study of flavopiridol in relapsed chronic lymphocytic leukemia demonstrating high response rates in genetically high-risk disease. J Clin Oncol. 2009; 27: 6012-6018.

22. Hahntow IN, Schneller F, Oelsner M, Weick K, Ringhausen I, Fend F, et al. Cyclin-dependent kinase inhibitor Roscovitine induces apoptosis in chronic lymphocytic leukemia cells. Leukemia. 2004; 18: 747-755.

23. Chen R, Wierda WG, Chubb S, Hawtin RE, Fox JA, Keating MJ, et al. Mechanism of action of SNS-032, a novel cyclin-dependent kinase inhibitor, in chronic lymphocytic leukemia. Blood. 2009; 133: 4637-4645.

24. Johnson AJ, Yeh YY, Smith LL, Wagner AJ, Hessler J, Gupta S, et al. The novel cyclin-dependent kinase inhibitor dinaciclib (SCH727965) promotes apoptosis and abrogates microenvironmental cytokine protection in chronic lymphocytic leukemia cells. Leukemia. 2012; 26: 25542557.

25. Polier G, Ding J, Konkimalla BV, Eick D, Ribeiro N, Köelher M, et al. Wogonin and related natural flavones are inhibitors of CDK9 that induce apoptosis in cancer cells by transcriptional suppression of Mcl-1. Cell Death Dis. 2011; 2: e182.

26. Shehata M, Schnabel S, Demirtas D, Hilgarth M, Hubmann $\mathrm{R}$, Ponath E, et al. Reconstitution of PTEN activity by CK2 inhibitors and interference with the PI3-K/Akt cascade counteract the antiapoptotic effect of human stromal cells in chronic lymphocytic leukemia. Blood. 2010; 116: 2513- 
2521.

27. Chen R, Guo L, Chen Y, Jiang Y, Wierda WG, Plunkett W. Homoharringtonine reduced Mcl-1 expression and induced apoptosis in chronic lymphocytic leukemia. Blood. 2011; 117: 156-164.

28. Lucas DM, Edwards RB, Lozanski G, West DA, Shin JD, Vargo MA, et al. The novel plant-derived agent silvestrol has B-cell selective activity in chronic lymphocytic leukemia and acute lymphoblastic leukemia in vitro and in vivo. Blood. 2009; 113: 4656-4666.

29. Lindqvist LM, Vikström I, Chambers JM, McArthur K, Anderson MA, Henley KJ, et al. Translation inhibitors induce cell death by multiple mechanisms and Mcl-1 reduction is only a minor contributor. Cell Death Dis. 2012; 3: e409.

30. Huber S, Oelsner M, Decker T, zum Büchenfelde CM, Wagner M, Lutzny G, et al. Sorafenib induces cell death in chronic lymphocytic leukemia by translational downregulation of Mcl-1. Leukemia. 2011; 25: 838-847.

31. Seth S, Johns R, Templin MV. Delivery and biodistribution of siRNA for cancer therapy: challenges and future prospects. Ther Deliv. 2012; 3: 245-261.

32. Lu PY, Xie F, Woodle MC. In vivo application of RNA interference: from functional genomics to therapeutics. Adv Genet. 2005; 54: 117-142.

33. Fernando TR, Rodriguez-Malave NI, Rao DS. MicroRNAs in B cell development and malignancy. J Hematol Oncol. 2012, 5: 7.

34. O'Brien S, Moore JO, Boyd TE, Larratt LM, Skotnicki AB, Koziner B, et al. 5-year survival in patients with relapsed or refractory chronic lymphocytic leukemia in a randomized, phase III trial of fludarabine plus cyclophosphamide with or without oblimersen. J Clin Oncol. 2009; 27: 5208-5212.

35. Yu B, Mao Y, Bai LY, Herman SEM, Wang X, Ramanunni A, et al. Targeted nanoparticule delivery overcomes offtarget immunostimulatory effects of oligonucleotides and improves therapeutic efficacy in chronic lymphocytic leukemia. Blood. 2013; 121: 136-147.

36. Lessene G, Czabotar PE, Colman PM. Bcl-2 family antagonists for cancer therapy. Nature Rev. 2008; 7: 9891000 .

37. Oltersdorf T, Elmore SW, Shoemaker AR, Armstrong RC, Augeri DJ, Belli BA, et al. An inhibitor of Bcl-2 family proteins induces regression of solid tumors. Nature. 2005; 435: 677-681.

38. Vogler M, Weber K, Dinsdale D, Schmitz I, SchulzeOsthoff K, Dyer MJS, et al. Different forms of cell death induced by putative BCL2 inhibitors. Cell Death Diff. 2009; 16: 1030-1039.

39. Albershardt TC, Salerni BL, Soderquist RS, Bates DJP, Pletnev AA, Kisselev AF, et al. Multiple BH3 mimetics antagonize antiapoptotic MCL-1 protein by inducing the endoplasmic reticulum stress response and up-regulating BH3-only protein NOXA. J Biol Chem. 2011; 286: 24882
24895.

40. Khaw SL, Huang DCS, Roberts AW. Overcoming blocks in apoptosis with BH3-mimetic therapy in hematological malignancies. Pathology. 2011; 43: 525-535.

41. Del Gaizo Moore V, Brown JR, Certo M, Love TM, Novina $\mathrm{CD}$, Letai A. Chronic lymphocytic leukemia requires BCL2 to sequester prodeath BIM, explaining sensitivity to BCL2 antagonist ABT-737. J Clin Invest. 2007; 117: 112-121.

42. Roberts AW, Seymour JF, Brown JR, Wierda WG, Kipps TJ, Carney DA, et al. Substantial susceptibility of chronic lymphocytic leukemia to BCL2 inhibition: results of a phase I study of navitoclax in patients with relapsed or refractory disease. J Clin Oncol. 2012; 30: 488-496.

43. Souers AJ, Leverson JD, Boghaert ER, Ackler SL, Catron ND, Chen J, et al. ABT-199, a potent and selective BCL2 inhibitor, achieves antitumor activity while sparing platelets. Nat Med. 2013; 19: 202-208.

44. Nguyen M, Marcellus RC, Roulston A, Watson M, Serfass L, Murthy Madiraju ST, et al. Small molecule obatoclax (GX15-070) antagonizes MCL-1 and overcomes MCL-1mediated resistance to apoptosis. Proc Natl Acad Sci USA. 2007; 104: 19512-19517.

45. Perez-Galan P, Roué G, Lopez-Guerra M, Nguyen M, Villamor N, Montserrat E, et al. BCL-2 phosphorylation modulates sensitivity to the BH3 mimetic GX15-070 (Obatoclax) and reduces its synergistic interaction with bortezomib in chronic lymphocytic leukemia cells. Leukemia. 2008; 22: 1712-1720.

46. Smoot RL, Blechacz BRA, Werneburg NW, Bronk SF, Sinicrope FA, Sirica AE, et al. A Bax-mediated mechanism for obatoclax-induced apoptosis of cholangiocarcinoma cells. Cancer Res 2010; 70: 1960-1969.

47. Joudeh J, Claxton D. Obatoclax mesylate: pharmacology and potential for therapy of hematological neoplasms. Expert Opin Investig Drugs. 2012; 21: 363-373.

48. Thomas S, Quinn BA, Das SK, Dash R, Emdad L, Dasgupta $\mathrm{S}$, et al. Targeting the Bcl-2 family for cancer therapy. Expert Opin Ther Targets. 2013; 17: 61-75.

49. van Delft MF, Wei AH, Mason KD, Vandenberg CJ, Chen L, Czabotar PE, et al. The BH3 mimetic ABT-737 targets selective Bcl-2 proteins and efficiently induces apoptosis via Bak/Bax if Mcl-1 is neutralized. Cancer Cell. 2006; 10: 389-399.

50. Billard C. Design of novel BH3 mimetics for the treatment of chronic lymphocytic leukemia. Leukemia. 2012; 26: 2032-2038.

51. Balakrishnan K, Wierda WG, Keating MJ, Gandhi V. Gossypol, a BH3 mimetic, induces apoptosis in chronic lymphocytic leukemia. Blood. 2008; 117: 1971-1980.

52. Balakrishnan K, Burger JA, Wierda WG, Gandhi V. AT101 induces apoptosis in CLL B cells and overcomes stromal cell-mediated Mcl-1 induction and drug resistance. Blood. 2009; 113: 149-153.

53. James DF, Castro JE, Loria O, Prada CE, Aguillon RA, 
Kipps TJ. AT-101, a small Bcl-2 antagonist, in treatment naïve CLL patients with high risk features; preliminary results from an ongoing phase I trial. J Clin Oncol. 2006; 24 (No 18S): 6605.

54. Balakrishnan K, Aggarwal S, Wierda W, Gandhi V. Bax and Bak are required for apogossypolone, a $\mathrm{BH} 3$ mimetic, induced apoptosis in chronic lymphocytic leukemia. Leuk Lymphoma. 2012; 54: 1097-1100.

55. Ghiotto F, Fais F, Tenca C, Tomati V, Morabito F, Casciaro $\mathrm{S}$, et al. Apoptosis of B-cell chronic lymphocytic leukemia cells induced by a novel BH3 peptidomimetic. Cancer Biol Ther. 2009; 8: 263-271.

56. Sampath D, Liu C, Vasan K, Sulda M, Puduvalli VK, Wierda WG, et al. Histone deacetylases mediate the silencing of miR-15a, miR-16, and miR-29b in chronic lymphocytic leukemia. Blood. 2010; 119: 1162-1172.

57. Aron JL, Parthun MR, Marcucci G, Kitada S, Mone AP, Davis ME, et al. Depsipeptide (FR901228) induces histone acetylation and inhibition of histone deacetylase in chronic lymphocytic leukemia cells concurrent with activation of caspase 8-mediated apoptosis and down-regulation of c-FLIP protein. Blood. 2003; 102: 652-658.

58. Inoue S, Riley J, Gant TW, Dyer MJS, Cohen GM. Apoptosis induced by histone deacetylase inhibitors in leukemic cells is mediated by Bim and Noxa. Leukemia. 2007; 21: 1773-1782.

59. El-Khoury V, Moussay E, Janji B, Palissot V, Aouali $\mathrm{N}$, Brons $\mathrm{NH}$, et al. The histone deacetylase inhibitor MGDC0103 induces apoptosis in B-cell chronic lymphocytic leukemia cells through a mitochondriamediated caspase activation cascade. Mol Cancer Ther. 2010; 9: 1349-1360.

60. Byrd JC, Marcucci G, Parthun MR, Xiao JJ, Klisovic RB, Moran M, et al. A phase 1 and pharmacodynamic study of depsipeptide (FK228) in chronic lymphocytic leukemia and acute myeloid leukemia. Blood. 2005; 105: 959-967.

61. Blum KA, Advani A, Fernandez L, Van Der Jagt R, Brandwein J, Kambhampati S, et al. Phase II study of the histone deacetylase inhibitor MGCD0103 in patients with previously treated chronic lymphocytic leukemia. Br J Haematol. 2009; 147: 507-514.

62. Inoue $\mathrm{S}$, Walewska $\mathrm{R}$, Dyer MJS, Cohen GM. Downregulation of Mcl-1 potentiates HDACi-mediated apoptosis in leukemic cells. Leukemia. 2008; 22: 819-825.

63. Frankland-Searby S, Bhaumik SR. The $26 \mathrm{~S}$ proteasome complex: an attractive target for cancer therapy. Biochim Biophys Acta. 2012; 1825: 64-76.

64. Fennell DA, Chacko A, Mutti L. BCL-2 family regulation by the $20 \mathrm{~S}$ proteasome inhibitor bortezomib. Oncogene. 2008; 27: 1189-1197.

65. Almond JB, Snowden RT, Hunter A, Dinsdale D, Cain $\mathrm{K}$, Cohen GM. Proteasome inhibitor-induced apoptosis of B-chronic lymphocytic leukemia cells involves cytochrome c release and caspase activation, accompanied by formation of an $700 \mathrm{kDa}$ Apaf-1 containing apoptosome complex. Leukemia. 2001; 15: 1388-1397.

66. Baou M, Kohlhaas SL, Butterworth M, Vogler M, Dinsdale B, Walewska R, et al. Role of Noxa and its ubiquitination in proteasome inhibitor-induced apoptosis in chronic lymphocytic leukemia cells. Haematologica. 2010; 95: 1510-1518.

67. Faderl S, Rai K, Gribben J, Byrd JC, Flinn IW, O’Brien $\mathrm{S}$, et al. Phase II study of single-agent bortezomib for the treatment of patients with fludarabine-refractory B-cell chronic lymphocytic leukemia. Cancer. 2006; 107: 916-924.

68. Nencioni A, Hua F, Dillon CP, Yokoo R, Scheiermann C, Cardone $\mathrm{MH}$, et al. Evidence for a protective role of $\mathrm{Mcl}$ 1 in proteasome inhibitor-induced apoptosis. Blood. 2005; 105: 3255-3262.

69. Gupta SV, Hertlein E, Lu Y, Sass EJ, Lapalombella R, Chen $\mathrm{TL}$, et al. The proteasome inhibitor carfilzomib functions independently of p53 to induce cytotoxicity and an atypical NF- $\square$ B response in chronic lymphocytic leukemia cells. Clin Cancer Res. 2013; 19: 2406-2419.

70. Zang Y, Thomas SM, Chan ET, Kirk CJ, Freilino ML, DeLancey HM, et al. The next generation proteasome inhibitors carfilzomib and oprozomib activate prosurvival autophagy via induction of the unfolded protein response and ATF4. Autophagy. 2012; 8: 1-2.

71. Chen D, Daniel KG, Chen MS, Kuhn DJ, Landis-Piwowar KR, Dou QP. Dietary flavonoids as proteasome inhibitors and apoptosis inducers in human leukemia cells. Biochem Pharmacol. 2005; 69: 1421-1432.

72. Yang H, Chen D, Cui QC, Yuan X, Dou QP. Celastrol, a triterpene extracted from the Chinese « Thunder of God Vine " is a potent proteasome inhibitor and suppresses human prostate cancer growth in nude mice. Cancer Res. 2006; 66: 4758-4765.

73. Kanwar J, Taskeen M, Mohammad I, Huo C, Chan TH, Dou QP. Recent advances on tea polyphenols. Front Biosci. 2012; 4: 111-131.

74. Quiney C, Dauzonne D, Kern C, Fourneron JD, Izard JC, Mohammad RM, et al. Flavones and polyphenols inhibit the NO pathway during apoptosis of leukemia B-cells. Leuk Res. 2004; 28: 851-861.

75. Piedfer M, Bouchet S, Tang R, Billard C, Dauzonne D, Bauvois B. p70S6 kinase is a target of the novel proteasome inhibitor 3,3'-diamino-4'-methoxyflavone during apoptosis in human myeloid tumor cells. Biochim Biophys Acta. 2013; 1833: 1316-1328.

76. Billard C, Merhi F, Bauvois B. Mechanistic insights into the antileukemic activity of hyperforin. Curr Cancer Drug Targets. 2013; 13: 1-10.

77. Quiney C, Billard C, Faussat AM, Salanoubat C, Ensaf A, Naït-Si Y, et al. Pro-apoptotic properties of hyperforin in leukemic cells from patients with chronic lymphocytic leukemia. Leukemia. 2006; 20: 491-497.

78. Zaher M, Akrout I, Mirshahi M, Kolb JP, Billard C. 
Noxa upregulation is associated with apoptosis of chronic lymphocytic leukemia cells induced by hyperforin but not flavopiridol. Leukemia. 2009; 23: 594-596.

79. Zaher M, Tang R, Bombarda I, Merhi F, Bauvois B, Billard C. Hyperforin induces apoptosis of chronic lymphocytic leukemia cells through upregulation of the BH3-only protein Noxa. Int J Oncol. 2012; 40: 269-276.

80. Happo L, Cragg MS, Phipson B, Haga JM, Jansen ES, Herold MJ, et al. Maximal killing of lymphoma cells by DNA damage-inducing therapy requires not only the p53 targets Puma and Noxa, but also Bim. Blood. 2010; 116: 5256-5267.

81. Mackus WJM, Kater AP, Grummels A, Evers ML, Hooijbrink B, Kramer MHH, et al. Chronic lymphocytic leukemia cells display p53-dependent drug-induced Puma upregulation. Leukemia. 2005; 19: 427-434.

82. Iglesias-Serret D, de Frias M, Santidrian AF, Coll-Mulet L, Cosialls AM, Barragan M, et al. Regulation of the proapoptotic BH3-only protein BIM by glucocorticoids, survival signals and proteasome in chronic lymphocytic leukemia cells. Leukemia. 2007; 21: 281-287.

83. Tonino SH, van Laar J, van Oers MH, Wang JY, Eldering E, Kater AP. ROS-mediated upregulation of Noxa overcomes chemoresistance in chronic lymphocytic leukemia. Oncogene. 2011; 30: 701-713.

84. Santidrian AF, Gonzalez-Gironès DM, Iglesias-Serret D, Coll-Mulet L, Cosialls AM, de Frias M, et al. AICAR induces apoptosis independently of AMPK and p53 through up-regulation of the $\mathrm{BH} 3$-only proteins BIM and NOXA in chronic lymphocytic leukemia cells. Blood. 2010; 116: 3023-3032.

85. Roué G, Lopéz-Guerra M, Milpied P, Pérez-Galan P, Villamor N, Montserrat E, et al. Bendamustine is effective in $\mathrm{p} 53$-deficient $\mathrm{B}$-cell neoplasms and requires oxidative stress and caspase-independent signaling. Clin Cancer Res. 2008; 14: 6907-6915.

86. Iglesias-Serret D, Piqué M, Barragan M, Cosialls AM, Santidrian AF, Gonzalez-Gironès DM, et al. Aspirin induces apoptosis in human leukemia cells independently of NF-kappaB and MAPKs through alteration of the Mcl-1/ Noxa balance. Apoptosis. 2010; 15: 219-229.

87. Steele AJ, Prentice AG, Hoffbrand AV, Yogashangary BC, Hart SM, Lowdell MW, et al. 2-phenylacetylenesulfonamide (PAS) induces p53-independent apoptotic killing of B-chronic lymphocytic leukemia (CLL) cells. Blood. 2009; 114: 1217-1225.

88. Alonso R, Lopez-Guerra M, Upshaw R, Bantia S, Smal C, Bontemps F, et al. Forodesine has high antitumor activity in chronic lymphocytic leukemia and activates p53independent mitochondrial apoptosis by induction of $\mathrm{p} 73$ and BIM. Blood. 2009; 114: 1563-1575.

89. Balakrishnan K, Verma D, B'Brien S, Kilpatrick JM, Chen $\mathrm{Y}$, Tyler BF, et al. Phase 2 and pharmacodynamic study of oral forodesine in patients with advanced, fludarabine- treated chronic lymphocytic leukemia. Blood. 2010; 116 : 886-92.

90. Shankar S, Singh G, Srivastava RK. Chemoprevention by resveratrol: molecular mechanisms and therapeutic potential. Front Biosci. 2007; 12: 4839-4854.

91. Roman V, Billard C, Kern C, Ferry-Dumazet H, Izard JC, Mohammad R, et al. Analysis of resveratrol-induced apoptosis in human B-cell chronic leukaemia. $\mathrm{Br} \mathrm{J}$ Haematol. 2002; 117: 842-851.

92. Billard C, Izard JC, Roman V, Kern C, Mathiot C, Mentz F, et al. Comparative antiproliferative and apoptotic effects of resveratrol, $\square$-viniferin and vine-shots derived polyphenols (vineatrols) on chronic lymphocytic leukemia cells and normal human lymphocytes. Leuk Lymphoma. 2002; 43: 1991-2002.

93. Ghosh AK, Kay NE, Secreto CR, Shanafelt TD. Curcumin inhibits prosurvival pathways in chronic lymphocytic leukemia B cells and may overcome their stromal protection in combination with EGCG. Clin Cancer Res. 2009; 15: 1250-1258.

94. Lee YK, Bone ND, Strege AK, Shanafelt TD, Jelinek DF, Kay NE. VEGF receptor phosphorylation status and apoptosis is modulated by a green tea component, epigallocatechin-3-gallate (EGCG), in B-cell chronic lymphocytic leukemia. Blood. 2004; 104: 788-794.

95. Shanafelt TD, Call TG, Zent CS, Leis JF, LaPlant B, Bowen DA, et al. Phase 2 trial of daily, oral Polyphenon $\mathrm{E}$ in patients with asymptomatic, Rai stage 0 to II chronic lymphocytic leukemia. Cancer. 2013; 119: 363-370.

96. Russo M, Spagnuolo C, Volpe S, Mupo A, Tedesco I, Russo GL. Quercetin induces apoptosis in association with death receptors and fludarabine in cells isolated from chronic lymphocytic leukaemia patients. Br J Cancer. 2010; 103: 642-648.

97. Russo M, Spagnuolo C, Volpe S, Tedesco I, Bilotto S, Russo GL. ABT-737 resistance in B-cells isolated from chronic lymphocytic leukemia patients and leukemia cell lines is overcome by the pleiotropic kinase quercetin through Mcl-1 down-regulation. Biochem Pharmacol. 2013; 85: 927-936.

98. Budhraja A, Gao N, Zhang Z, Son YO, Cheng S, Wang X, et al. Apigenin induces apoptosis in human leukemia cells and exhibits anti-leukemic activity in vivo. Mol Cancer Ther. 2012; 11: 132-142.

99. Lust S, Vanhoecke B, Van Gele M, Boelens J, Van Melckebeke H, Kaileh M, et al. Xanthohumol activates the proapoptotic arm of the unfolded protein response in chronic lymphocytic leukemia. Anticancer Res. 2009; 29: 3797-3806.

100. Inoue S, Snowden RT, Dyer MJ, Cohen GM. CDDO induces apoptosis via the intrinsic pathway in lymphoid cells. Leukemia. 2004; 18: 948-952.

101. Kress CL, Konopleva M, Martinez-Garcia V, Krajewsla M, Lefebvre S, Hyer M, et al. Triterpenoids display single 
agent anti-tumor activity in a transgenic mouse model of chronic lymphocytic leukemia and small B cell lymphoma. PLoS One. 2007; 2: e559.

102. Shan T, Ma Q, Guo K, Liu J, Wang F, WU E. Xanthones from mangosteen extracts as natural chemopreventive agents: potential anticancer drugs. Curr Mol Med. 2011; 11: 666-677.

103. Menasria F, Azebaze AG, Billard C, Faussat AM, Nkengfack AE, Meyer $M$, et al. Apoptotic effects on B-cell chronic lymphocytic leukemia (B-CLL) cells of heterocyclic compounds isolated from Guttiferaes. Leuk Res. 2008; 32: 1914-1926.

104. Loisel S, Le Ster K, Meyer M, Youinou P, Kolb JP, Billard C. Therapeutic activity of two xanthones in a xenograft murine model of human chronic lymphocytic leukemia. J Hematol Oncol. 2010;3:49.

105. Fang L, Shen L, Fang Y, Hu H, He Q, Yang B. MZ3 can induce G2/M-phase arrest and apoptosis in human leukemia cells. J Cancer Res Clin Oncol. 2008; 134: 1337-1345.

106. Billard C, Menasria F, Quiney C, Faussat AM, Finet JP, Combes S, et al. 4-arylcoumarin analogues of combretastatins stimulate the apoptosis of leukemic cells from chronic lymphocytic leukemia patients. Exp Hematol. 2008; 36: 1625-1633.

107. Bates DJ, Danilov AV, Lowrey CH, Eastman A. Vinblastine rapidly induces Noxa and acutely sensitizes primary chronic lymphocytic leukemia cells to ABT-737. Mol Cancer Ther. 2013; 12: 1504-1514.

108. Bruno S, Ghiotto F, Tenca C, Mazzarello AN, Bono M, Luzzi $\mathrm{P}$, et al. N-(4-hydroxyphenyl) retinamide promotes apoptosis of resting and proliferating B-cell chronic lymphocytic leukemia cells and potentiates fludarabine and ABT-737 cytotoxicity. Leukemia. 2012; 26: 2260-2268.

109. LaCasse EC, Mahoney DJ, Cheung HH, Plenchette S, Baird S, Korneluk RG. IAP-targeted therapies for cancer. Oncogene 2008; 27: 6252-6275.

110. Gowda A, Roda J, Hussain SR, Ramanunni A, Joshi T, Schmidt S, et al. IL-21 mediates apoptosis through upregulation of the $\mathrm{BH} 3$ family member BIM and enhances both direct and antibody-dependent cellular cytotoxicity in primary chronic lymphocytic leukemia cells in vitro. Blood. 2008; 111: 4723-4730.

111. Zeitlin BD, Nör JE. Small-molecule inhibitors reveal a new function for Bcl-2 as a proangiogenic signaling molecule. Curr Top Microbiol Immunol. 2011; 348: 115-137.

112. Aijar SE, Park H, Aldo PB, Mor G, Gildea JJ, Miller AL, et al. TMS, a chemically modified herbal derivative of Resveratrol, induces cell death by targeting Bax. Breast Cancer Res Treat. 2010; 124: 265-277.

113. Hsu YL, Kuo PL, Lin CC. Isoliquiritigenin induces apoptosis and cell cycle arrest through p53-dependent pathway in Hep G2 cells. Life Sci. 2005; 77: 279-292.

114. Yu F, Watts RN, Zhang XD, Borrow JM, Hersey P. Involvement of $\mathrm{BH} 3-$ only proapoptotic proteins in mitochondrial-dependent Phenoxodiol-induced apoptosis of human melanoma cells. Anticancer Drugs. 2006; 17: 11511161.

115. Dai Y, DeSano J, Tang W, Meng X, Meng Y, Burstein E, et al. Natural proteasome inhibitor celastrol suppresses androgen-independent prostate cancer progression by modulating apoptotic proteins and NF-kappaB. PLoS One. 2010; 5: e14153.

116. Tromp JM, Geest CR, Brej EC, Elias JA, van Laar J, Luiks $\mathrm{DM}$, et al. Tipping the Noxa/Mcl-1 balance overcomes ABT-737 resistance in chronic lymphocytic leukemia. Clin Cancer Res. 2012; 18: 487-498.

117. Billard C. Development of Noxa-like BH3 mimetics for apoptosis-based therapeutic strategy in chronic lymphocytic leukemia. Mol Cancer Res. 2012; 10: 673-676.

118. Cohen NA, Stewart ML, Gavathiotis E, Tepper JL, Bruekner SL, Koss B, et al. A competitive stapled peptide screen identifies a selective small molecule that overcomes Mcl-1-dependent leukemia cell survival. Chem Biol. 2012; 19: $1175-1186$.

119. LaBelle JL, Katz SG, Bird GH, Gavathiotis E, Stewart ML, Lawrence C, et al. A stapled Bim peptide overcomes apoptotic resistance in hematologic cancers. J Clin Invest. 2012; 122: 2018-2031.

120. Gavathiotis E, Reyna DE, Bellairs JA, Leshchiner ES, Walensky LD. Direct and selective small-molecule activation of proapoptotic BAX. Nat Chem Biol. 2012; 8: 639-645. 